\title{
Multilevel Modeling of the Forest Resource Dynamics
}

\author{
I.N. Vladimirov ${ }^{1}$, A.K. Chudnenko ${ }^{2}$ \\ ${ }^{1}$ V.B. Sochava Institute of Geography SB RAS, Irkutsk, Russia \\ ${ }^{2}$ Institute for System Dynamics and Control Theory of SB RAS, Irkutsk, Russia
}

\begin{abstract}
We examine the theoretical and applications-specific issues relating to modeling the temporal and spatial dynamics of forest ecosystems, based on the principles of investigating dynamical models. When developing the predictive dynamical models of forest resources, there is a possibility of achieving uniqueness of the solutions to equations by taking into account the initial and boundary conditions of the solution, and the conditions of the geographical environment. We present the results of a computer modeling and predictive mapping for the regional and subregional model of the forest resource dynamics.
\end{abstract}

Key words: forest resource dynamics, GIS, temporal and spatial dynamics of forest ecosystems, regional and subregional model of forest resources

AMS subject classification: 92D40

\section{Introduction}

In forest science, relatively advanced mathematical modeling systems have been developed for the forest dynamics on different levels of their organization: local - models of an individual tree and forest stands [1]-[9], subregional - description of the changes in the distribution of forested areas in species and age classes, and in stages of regeneration dynamics [4], [10]-[13], regional - equations of redistribution of biomass reserves in species [14]-[16], and global - reflection of the role and place of forest ecosystems in the cycle of matter and energy [17]. In recent years, with an enhancement in computational power of personal computers, it was possible to develop hierarchical structural models for forest ecosystems [18]-[21].

*Corresponding author. E-mail: garisson@irigs.irk.ru 
Modeling is also supported by a variety of mathematical tools. The models of development of ecosystems can be divided into two large classes: 1) continuous (on the basis of ordinary differential equations for lumped models, and on partial differential equations for spatially distributed systems), and 2) discrete (on the basis of systems of algebraic equations which, in most cases, can be obtained by discretization of differential equations; in the spatially distributed case, they are characteristic models called cellular automata).

Unfortunately, each of the models, perfect as it may be, can only be used in solving a narrow class of prediction and planning problems. A practical implementation of forest resource management involves developing an integral multilevel system of models. The hierarchy of models for the dynamics of forest stands must include three levels, as a minimum: 1) calculating the dynamics of spatial distribution of uneven-aged and multiple-species stands in a forest unit having regard to forestry-related activity, and 3) the regional model with district forestry-level data aggregation.

One of the principal requirements for such models is to use, as initial information, the forest inventory data (obtained in a district forestry) which are convenient for the analysis of the forest resources because of their frequent recurrence interval and an adequate degree of detail which are necessary to the solution of theoretical and practical prediction problems, in view of the consequences of different kinds of economic activities and disastrous successions. Such models must be easily adjustable for the particular physical-geographical conditions and be supported by a userfriendly interface.

\section{Model and methods}

A modeling of the development of forest stands must take into consideration that separate tracts of forest are open systems whose dynamics is governed both by the state of the physical-geographical conditions of environment and by the influence of neighboring forest ranges. Therefore the mathematical description of such processes and connections requires a model with distributed parameters in which the main characteristics of forest are functions of spatial coordinates and depend on the influence of surrounding elements of a system under investigation.

\subsection{Uniqueness of models for the forest resource dynamics}

When mathematical methods are used in forecasting natural phenomena, the question as to whether the basic model equations conform to the properties of real geographical systems often remains unsolved. This problem is most often encountered in the analysis of dynamical systems of wildlife.

The mathematical model of a geographical process is represented by its description in mathematical terms matching the initial concepts and data. The simplest model is a list of the properties of environment and its dynamic parameters whose interrelationship describes the process under study within a given approximation to the reality.

When investigating and modeling geographical objects, for specifying the uniqueness conditions and identifying independent variables it is necessary to determine exactly: 1) the geometrical and topological properties of the system in which the process is taking place (characteristic of the 
relief, facies structure, etc.); 2) important (for this process) characteristics of the objects comprising the system, and their dependence on state parameters and dynamic impacts (such as the forested area, the intensity coefficients of state-to-state transition, etc.); 3) the initial or final state of the system, and 4) the conditions on the boundaries of the system during the course of the process [22].

The dimensional quantities, corresponding to this list, and their values determine the uniqueness conditions of the geographical process, and identify a single phenomenon of a given class as the geographical situation. The quantities, involved in the uniqueness condition, are specified externally with respect to the basic equations and are, therefore, independent variables, the set of which uniquely defines the behavior of a particular process. The other variables involved in the basic equations, all are dependent variables [22].

By considering an example of the model for the forest resource dynamics which reflects the changes in the distribution of forested areas in species and age classes, we now illustrate the specification of the uniqueness conditions resulting in the generation of the model which specifically determines the process in some geographical situation.

A change in the structure of forest stands, in view of species succession, is represented by a system of differential equations of the form

$$
d S_{i j} / d t=p_{i j-1} \alpha_{i} S_{i j-1}-p_{i j} \alpha_{i} S_{i j}-\gamma_{i j} S_{i j}+{ }_{i} I_{i j}(t),
$$

where $S_{i j}(t)$ is the area occupied by forests, with the $i$-th species of the $j$-th age class at the time $t$ (ha) predominating; $\alpha_{i j}=p_{i j} \alpha_{i}$ is the transition intensity of the area of forests of the $i$-th species of the $j$-th age class to the area of forests of the same species of the $(i+1)$-th age class (1/year); $\gamma_{i j}=p_{0 i j} \alpha_{i}$ is intensity factor of succession of the $i$-th species of the $j$-th age class to forests of other species and ages (1/year); $p_{i j}$ is the share of the area in which the forest of a given species persists in the process of forest regeneration-age dynamics, $p_{0 i j}$ - where it is replaced by forest stands, with other species $\left(p_{i j}=1-p_{0 i j}\right)$ predominating, and $I_{i j}$ is the total transition rate of forest stands of differing species composition and different ages to forest stands of the $i$-th species of the $j$ - th age. The value of $a_{i}$ is determined by the formula

$$
\alpha_{i}=1 / \Delta \tau_{i},
$$

where $\Delta \tau_{i}$ corresponds to the step of dividing the age into classes (40 years for Siberian stone pine, 20 years for the other coniferous species, and 10 years for deciduous species). Since the intensity and directedness of the species succession processes depends of spatial variation of physicalgeographical characteristics of the environment, the values of the variables $\gamma_{i j}$ are determined by landscape structure.

We substitute (2.2) into equation (2.1) and introduce the notation $\Delta S_{i j}=S_{i j}-S_{i j-1}$; then we have $d S_{i j} / d t=-\Delta S_{i j} / \Delta \tau_{i}$. In the case of an infinitely small step of dividing the age into classes $\Delta \tau_{i}=\Delta \tau \rightarrow 0$, the system of equations (2.1) is brought to a partial differential equation

$$
\partial S_{i}(t, \tau) / \partial t+\partial\left[p_{i}(t, \tau) S_{i}(t, \tau)\right] / \partial \tau=-\gamma_{i}(\tau) S_{i}(t, \tau)+I_{i}(t, \tau)
$$


where $S_{i}(t, \tau)$ is the forested area, with the $i$-th species of age $\tau$ at the time $t$ predominating; $\gamma_{i}(\tau)$ is the transition intensity of forest stands, with the $i$-th species of age $\tau$ predominating in the forest stands of other species; $p_{i}(t, \tau)$ is the probability that the forest stand, with the $i$-th species of age $\tau$ at time $t$, there occurs no species succession, and $I_{i}(t, \tau)$ is the total transition rate of forest stands of a different species composition and of different ages to forest stands of the $i$-th species of age $\tau$ at time $t$.

The dependent variable sin the model are represented by the forested area $\left(S_{i}\right)$, and by the rate at which the forests of different species are replaced by forest stands of a given species composition and a given age $\left(I_{i}\right)$. The independent variables are first and foremost a constant $p_{i}$ and a constant $\gamma_{i}$, as well as the initial $S_{i}(0, \tau)=S_{\mathrm{H} i}(\tau)$ and boundary conditions $S_{i}(\tau, 0)=\alpha_{i}^{0} S_{0 i}(\tau)$ of the solution (2.3). The probabilities $p_{j}$ and $p_{0 i}$ are specified externally with respect to the main variables of the model equations are define uniquely the dynamics of forest stands under particular physical-geographical conditions which govern the intensity and directedness of species succession in different localities.

Identifying such geographical linkages is an important part of illustrating the conditions of ensuring the uniqueness of realization of predictive-analytical models.

By way of example let us consider in terms of the area model for the regeneration-age dynamics of forests $(2.3)$ a stationary process $\left(\partial S_{i} / \partial t=0\right)$ of destruction of mature and overmature forest stands where there is no increase in the areas due to a succession of forests, with other species and ages predominating $\left(I_{i}=0\right)$ :

$$
\partial\left(p_{i}(\tau) S_{i}(\tau)\right) / \partial \tau=-\gamma_{i}(\tau) S_{i}(\tau),
$$

where $\gamma_{i}(\tau)=\left(1-p_{i}\right) / \Delta \tau_{i}$. Assuming that $p_{i}$ is age-independent and substituting $n_{i}=\tau / \Delta \tau_{i}$, i.e. using age classes i.e. $n_{i}$ instead of age $\tau$, we obtain $\frac{\partial S_{i}\left(n_{i}\right)}{\partial n_{i}}=-k_{i} S_{i}\left(n_{i}\right), k_{i}=\frac{1-p_{i}}{p_{i}}$. The solution to this differential equation is obtained with the boundary condition $S_{i}\left(n_{0 i}\right)=S_{0 i}$ :

$$
S_{i}\left(n_{i}\right)=S_{0 i} \exp \left(-k_{i}\left(n_{i}-n_{0 i}\right)\right)
$$

where $n_{0 i}$ is an age class for the onset of forest destruction (maturity age).

The coefficients $k_{i}$ and $\ln S_{0 i}$ are calculated by linear regression methods according to the scheme obtained from equation (2.4) upon taking the logarithm:

$$
\ln S_{i}\left(n_{i}\right)=\ln S_{0 i}-k_{i}\left(n_{i}-n_{0 i}\right),
$$

The coefficients of destruction intensity of overmature forests were calculated for the district forestries of the Irkutsk region. If $S_{0 i}$ is calculated in fractions of the area of mature and overmature forest stands of the $i$-th species, then the values of the coefficients $k_{i}$ and $\ln S_{0 i}$ in (2.5) are found to be correlated

$$
\ln S_{0 i}+k_{i} n_{i 0}=6,46 k_{i}+10,03, R=-0,93,
$$

i.e. the linear dependencies (2.5) form a congruence with the node at the point $n_{i}=6,46, \ln S_{0 i}=$ 10, 03 (Fig.1). Equation (2.6) shows that the destruction process of overmature forest stands depends only on one indicator $k_{i}$, which characterizes the particular forest growth conditions, i.e. 
being the index of the environment with respect to the process under consideration, on the basis of which we calculate the value of $p_{i}=1 / k_{i}+1$, the reliability index of forest preservation, i.e. the larger is the $k_{i}$, the smaller is the share of the area in which, in the process of regeneration-age dynamics, forests of a given species survive. A knowledge of the value of the index $k_{i}$ makes it possible to take into consideration the specific character of the conditions and to change - when modeling the dynamics of forest stand structure - from some computational equations to the others, which ensures uniqueness of the computational scheme, and an integral consideration of the physical-geographical characteristics of the territory. This transition is accomplished by simply rotating the line of the dependence (2.5) about the nodal point of congruence (Fig.1): the processes in one environment are transformed (calibrated) to the process under different conditions according to the index $k_{i}$.

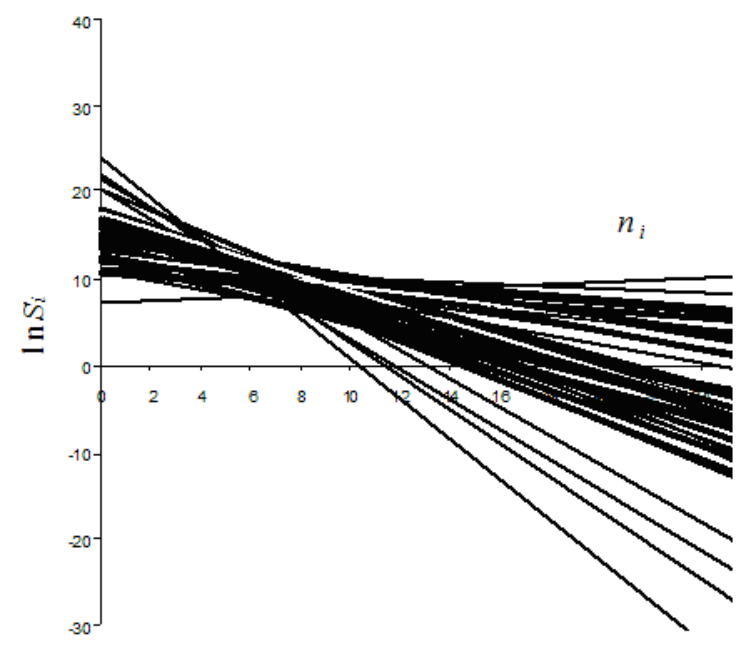

Figure 1: The area of overmature forests $S_{i}$ vs. age class $n_{i}$ at different $k_{i}$ on a semilogarithmic scale

Thus, when developing predictive dynamical models for taiga geosystems, it is possible to achieve satisfaction of the uniqueness condition of the solution to the equations by taking into consideration the initial and boundary conditions of the geographical environment. In the latter case, this is accomplished through the use of the indices of environment $k_{i}$ that determine the values of constants of the fundamental dependencies of the parameters of the natural system. Consequently, there exist some regularities of a continuous transition according to the index of environment from models developed for some conditions to models for other conditions.

\subsection{The local-level models}

The local-level mathematical models are based on the system of first-order partial differential equations [13] describing a time variation of the distribution of trees of the $i$-th species in the charac- 
teristic size $\rho$ (in the diameter in this case) in the unit vicinity of the point $\xi_{0}$ with coordinates ( $x$, $y)$ :

$$
\frac{\partial n^{i}}{\partial t}+\frac{\partial}{\partial \rho}\left[v^{i}\left(t, \rho, \xi_{0} ; N\right) n^{i}\right]=-a_{0}^{i}\left(t, \rho, \xi_{0} ; N\right) n^{i}-u^{i}, i=\overline{1, l},
$$

where $l$ is the number of forest-forming species within the area under consideration; $n^{i}\left(t, \rho, \xi_{0}\right)$ is the number of trees of the $i$-th species per unit vicinity of the point with coordinates $\xi_{0}$ and $\rho$; the coefficients $\alpha^{i}(\cdot)$ and $v^{i}(\cdot)$ correspond to the dieback intensity and growth rate of trees; $N$ is the total crowding level of the forest stand; $u^{i}\left(t, \rho, \xi_{o}\right)$ is the number of trees cut or planted per unit time, of diameter $\rho$ at time $t$ in the vicinities of the point $\xi_{0}$.

The interrelationship of the different localities in the model is reflected, firstly, through the transfer of seeds; therefore, $n_{H}^{i}(\cdot)$ is the distribution function of seed plants throughout the territory under investigation; secondly, through the environment-forming influence of forest stands on the surrounding localities. In doing calculations, the number germinating seedlings was calculated by the formula

$$
n_{s}^{i}\left(t, 0, \xi_{0}\right)=\left(n_{y}^{i}\left(t, \xi_{0}\right)+n_{s}^{i}\left(t, \xi_{0}\right)\right) \cdot \varphi_{R}^{i}\left(R_{0}\right) \times \iint_{S} \gamma\left(\xi_{0}, \xi_{1}\right) \cdot P\left(\xi_{1}\right) d \xi_{1},
$$

where $\varphi_{R}^{i}\left(R_{0}\right)$ if a function of the illumination influence (or the shade density) under the canopy layer $\left(R_{0}\right)$ on the appearance and survival of germinating seedlings; $P\left(\xi_{1}\right)$ is total crown closure of trees in the unit vicinity of the point $\xi_{1}$, and $\gamma\left(\xi_{0}, \xi_{1}\right)$ is a characteristic of the influence of crown closure of forest stands at the point $\xi_{i}$ on forest regeneration at the point $\xi_{0}$ (a decreasing function of distance from $\xi_{1}$ to $\xi_{0}$ ).

In equation (2.8), the physical-geographical background was taken into account directly in the values of $n_{v}^{i}(\cdot)$ and $n_{s}^{i}(\cdot)$, and the effect of the biogeocenotic conditions is related to illumination under the canopy layer and to crown closure of forest stands. This provides a means of reflecting some distinctive features of the regeneration process. Crown closure serves as the regulator of the biomass of grass cover; an increase in the biomass decreases, especially in felled areas, the number of tree sprouts. On the other hand, an increase in crown closure impairs the illumination conditions under the canopy layer and leads to a decay of the regeneration process and, at the same time, to a decrease in the biomass of herbaceous plants. The appearance of viable vegetative sprouts is signaled by an abrupt decrease in tree crown closure after, for example, fires, fellings, and propagation of parasites. The model takes into account such an effect by comparing the value of the closure index at contiguous steps of numerical integration.

This model handles information from the level of data on each forest unit. It can be used to create local tables of growth behavior, and in planning selective fellings for reconstructing forest stands, for example.

\subsection{The subregional-level models}

Models of this level are of the greatest applicational significance in contemporary conditions, as they describe the forest dynamics in terms of a variation in the distribution of their areas and 
reserves across time and space. It is possible to describe in these terms a change in the structure of forests from a region's level as a whole to the dynamics of internal areal structure of forest stands in an individual forest compartment.

The subregional-level model reflects the dynamics of forest reserves of the forest raw-materials base according to land categories and age groups: the forestless area $\left(S_{H}\right)$, the area uncovered in forest $\left(S_{0}\right)$, the area covered in forest, including in young growth and average-aged forest $\left(S_{1}\right)$, and in maturing $\left(S_{2}\right)$, mature and overmature forests $\left(S_{3}\right)$. The characteristics of the area $S_{i}\left(t, \xi_{1}\right)$ are spatially distributed and vary over time. The dynamics of these indices is described by the formulas [13]

$$
\begin{gathered}
d S_{H} / d t=-\lambda_{H 0} S_{H}\left(t, \xi_{1}\right)+\lambda_{0 H} S_{0}\left(t, \xi_{1}\right)+u_{H}\left(t, \xi_{1}\right) \\
d S_{0} / d t=-\lambda_{01} S_{0}\left(t, \xi_{1}\right)+\lambda_{H 0} S_{H}\left(t, \xi_{1}\right)-\lambda_{0 H} S_{0}\left(t, \xi_{1}\right)+\sum_{j} u_{j}\left(t, \xi_{1}\right)-u_{H 0}\left(t, \xi_{1}\right) \\
d S_{1} / d t=\lambda_{01} S_{0}\left(t, \xi_{1}\right)-\lambda_{12} S_{1}\left(t, \xi_{1}\right)-u_{1}\left(t, \xi_{1}\right)-u_{H 1}\left(t, \xi_{1}\right) \\
d S_{2} / d t=\lambda_{12} S_{1}\left(t, \xi_{1}\right)-\lambda_{23} S_{2}\left(t, \xi_{1}\right)-u_{2}\left(t, \xi_{1}\right)-u_{H 2}\left(t, \xi_{1}\right) \\
d S_{3} / d t=\lambda_{23} S_{2}\left(t, \xi_{1}\right)-u_{3}\left(t, \xi_{1}\right)-u_{H 3}\left(t, \xi_{1}\right)
\end{gathered}
$$

where $\lambda$ is the intensity coefficient of transition of the area from one category of lands or age group to the other; $u_{j}\left(t, \xi_{1}\right)$ is the annual are of fellings in forest stands of the $j$-th age group at time $t$ in the unit vicinity of the point $\xi_{1} ; u_{H}\left(t, \xi_{1}\right)$ is an increase in the forestless area in the course of capital construction through the other categories of lands $\left(u_{H i}\right)$.

The relative simplicity of the model and of its information support make it possible to calculate the estimation of rational forest management for significant territories. Data of compartment results are used as initial information. The level of spatial resolution of such data corresponds to the size of the compartments, which is equal (according to the different categories of forest organization) to the $2 \times 4 \mathrm{~km}^{2}$ or $1 \times 2 \mathrm{~km}^{2}$ rectangles. A compartment becomes an elementary cell of management in this case, and it is considered uniform (in natural characteristics) plot of the forest territory. The areas and the reserves of forest stands, with due regard for their distribution in age groups, become the main variables.

\subsection{The regional-level models}

The regional-level model uses the following variables: the total forestless area $\left(S_{H}\right)$ of the territory; the total area uncovered in forest $\left(S_{i 0}\right)$; the area covered in forest, with the $i$-th species predominating, including in young forest of the first $\left(S_{i 1}\right)$ and the second $\left(S_{i 2}\right)$ age classes; and in average-aged forests $\left(S_{i 3}\right)$; maturing $\left(S_{i 4}\right)$, mature $\left(S_{i 5}\right)$ and overmature $\left(S_{i 6}\right)$ forest stands. These dependencies are all time-dependent. The dynamics of these indices is described by the formulas: 


$$
\begin{gathered}
d S_{H} / d t=-\lambda_{H 0} S_{H}(t)+u_{H}(t) ; d S_{0} / d t= \\
-\lambda_{01} S_{0}(t)+\lambda_{H 0} S_{H}(t)+u_{P}(t)+u_{G}(t)-u_{0 H}(t)-u_{K}(t) \\
u_{P}(t)=\sum_{i, j} u_{P i j}(t) ; u_{K}(t)=\sum_{i} u_{K i}(t) ; u_{H}(t)=\sum_{i, j} u_{H i j}(t)+\sum_{i}\left(u_{H o i}(t)+u_{H K i}(t)\right) \\
d S_{K i} / d t=-\lambda_{K 1 i} S_{K i}(t)+u_{K i}(t)+u_{K H i}(t)-u_{G K i}(t) \\
d S_{i 1} / d t=\lambda_{K 1 i} S_{K i}(t)+\lambda_{01} p_{0 i} S_{0}(t)-\lambda_{12 i} S_{i 1}-u_{P i 1}(t)-u_{H i 1}(t)-u_{G i 2}(t) \\
d S_{i 2} / d t=\lambda_{12 i} S_{i 1}(t)-\lambda_{23 i} S_{i 2}(t)-u_{P i 2}(t)-u_{H i 2}(t)-u_{G i 2}(t) \\
d S_{i 3} / d t=\lambda_{23 i} S_{i 2}(t)-\lambda_{34 i} S_{i 3}(t)-u_{P i 3}(t)-u_{H i 3}(t)-u_{G i 3}(t)+I_{i} \\
d S_{i 4} / d t=\lambda_{34 i} S_{i 3}(t)-\lambda_{45 i} S_{i 4}(t)-u_{P i 4}(t)-u_{H i 4}(t)-u_{G i 4}(t) \\
d S_{i 5} / d t=\lambda_{45 i} S_{i 4}(t)-\lambda_{56 i} S_{i 5}(t)-u_{P i 5}(t)-u_{H i 5}(t)-u_{G i 5}(t) \\
d S_{i 6} / d t=\lambda_{56 i} S_{i 5}(t)-u_{P i 6}(t)-u_{H i 6}(t)-u_{G i 6}(t)-I_{i}
\end{gathered}
$$

where $\lambda_{j K i}$ is the intensity coefficient of transition of the area from one $(j)$ category of lands or a group of ages to the other $(K)$ for forests, with the $i$-species predominating, or for a definite category of lands (without the index $i$ ); $p_{0 i}$ is the share of the areas uncovered in forest, with expanding young growth and with the $i$-th species predominating; $u_{p i j}(t)$ is the annual logging area in forest stands of the $i$-th species of the $j$-th age group at time $t ; u_{H}(t)$ is an increase in the forestless area in the course of capital construction through the other categories of lands $\left(u_{H i j}\right)$; $u_{K}(t)$, and $u_{K i}(t)$, respectively, correspond to the annual area of logging as a whole, and to crops of the $i$-th species; $u_{G}(t), u_{G K i}(t)$, and $u_{G i j}(t)$, respectively, are the annually burnt-over area as a whole of crops of the $i$-th species and forests of the $i$-th species of the $j$-th age; $I_{i}$ stands for the growth rate of the area of average-aged forests of young growth of the $i$-th species as a result of species succession, and $I_{i}$ is the decrease rate of the area of overmature forests as a result of species succession.

The mathematical model was implemented by software on a personal computer, the issue relating to its information support with reference to the region's conditions was settled; forest organization information was used in solving prediction problems, and the validity of the model was verified using retrospective analysis. The year 1973 was chosen as the initial time of calculations 
in the model, as that year was supported by reliable information on the conditions of the forest resources obtained on the basis of forest inventory data.

Fig.2 $a$ plots the temporal dynamics of the forest resources (1973-2023) having regard to natural species succession as well as fellings and fires (a constant increase in felling of coniferous forests is assumed), and the withdrawal of forests of the forest reserves as a result of capital construction, and the process of creation of forest crops and their conversion to young growth. The natural dynamics of forest ranges in the absence of anthropogenic impacts was regarded as one of the variants of a predictive calculation (Fig.2b). A characteristic property of the behavior of the forest system in this case is represented by the increase in the areas of forests of light-coniferous species and Siberian stone pine, and the decrease in the area of birch forests. There is taking place a dramatic decrease in the areas of lands uncovered in forest. This reflects an ecologically natural and characteristic (for the Irkutsk region) dynamics of taiga forests.
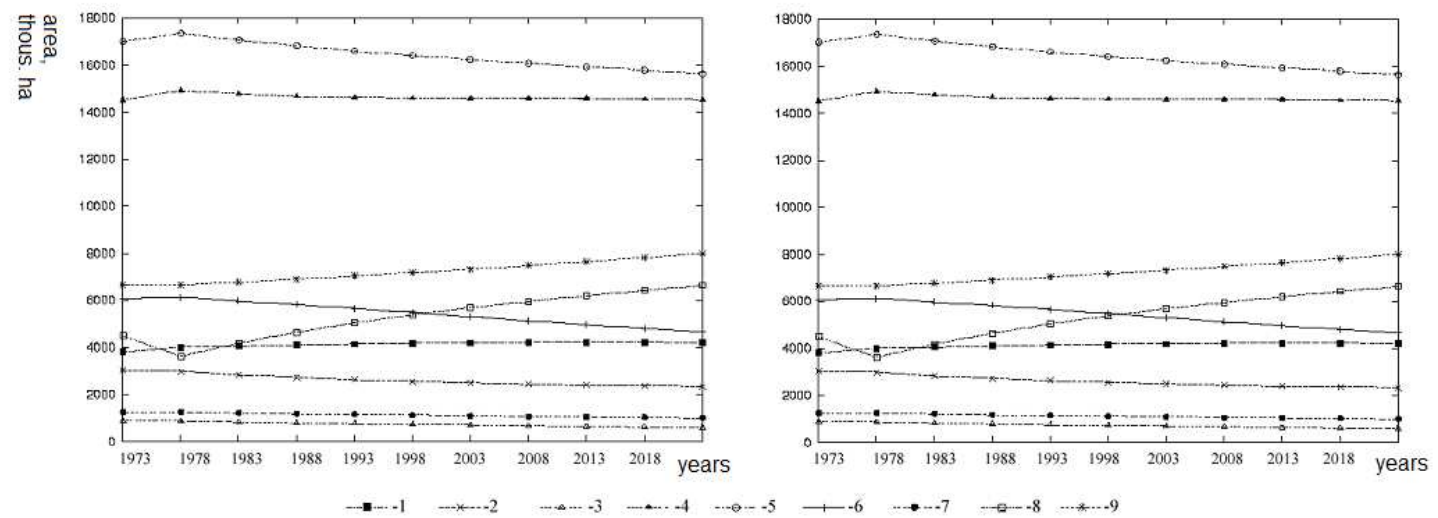

Figure 2: The plots of $a$ - the natural and anthropogenic temporal dynamics of forest resources (1973-2023), $b$ - the natural temporal dynamics of forest resources (1973-2023) (1 - Siberian stone pine, 2 - spruce, 3 - fir, 4 - pine, 5 - larch, 6 - birch, 7 - aspen, 8 - forest-unclad area, 9 forestless area)

The tendencies for a change in calculated and observed characteristics of the dynamics of forest areas in the Irkutsk region coincide, which points to the validity of the model, and to the possibility of using it in prediction and optimization calculations (Fig.3). It follows from the results of prediction calculations for the period before 2023 that the areas of forests, with larch and birch predominating, will be changing the most dynamically: the areas of birch and larch forest stands decrease as a result of logging operations, whereas the areas occupied by birch and aspen will be increasing due to predominant regeneration of this species in logged and burned-over areas. The areas of pine forests remain on a certain level due to reforestation (the calculations assumed an increase of the creation of new crops, with an increase in the felling volume). The calculations showed a significant increase in forestless areas, which is associated mainly with the increase of housing development, the increase in the areas of agricultural lands, capital construction and the production activities of the enterprises, and with the increase in the areas uncovered in forest because of fires and main fellings. 

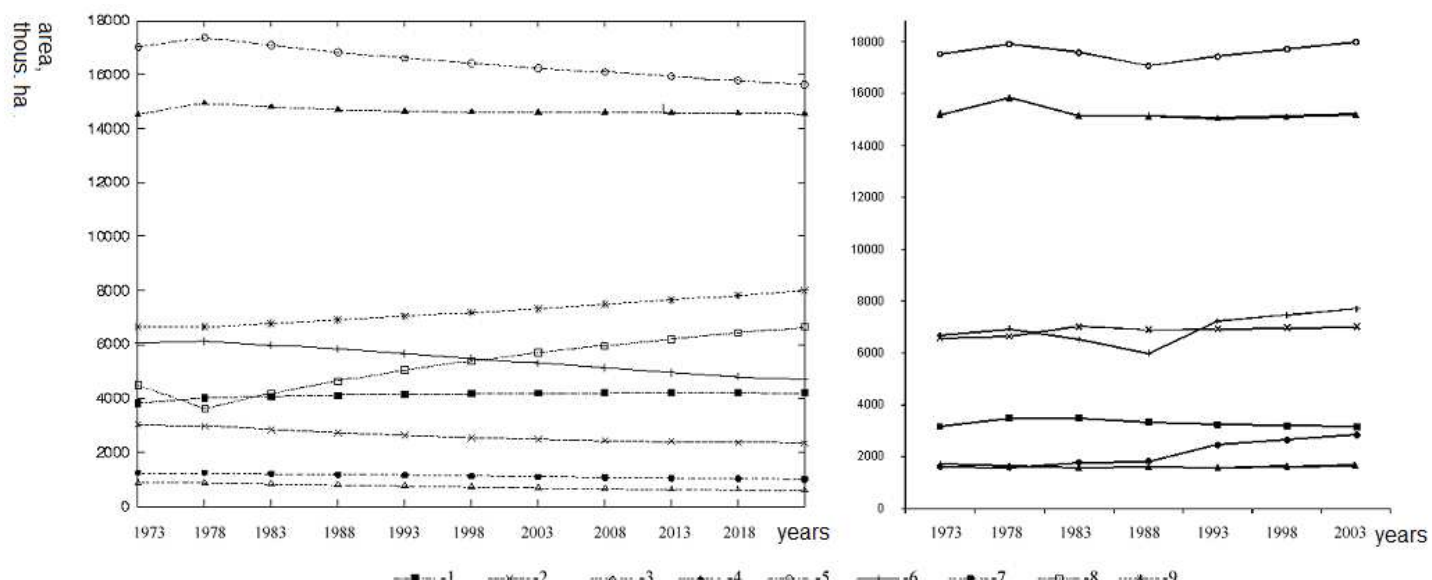

Figure 3: Comparison of calculated and observed characteristics of the dynamics of forest areas in the Irkutsk region ( 1 - Siberian stone pine, 2 - spruce, 3 - fir, 4 - pine, 5 - larch, 6 - birch, 7 aspen, 8 - forest-unclad area, 9 - forestless area)

\subsection{The modeling scenarios and multicriteria optimization}

When performing calculations in terms of the models, the user can access (to make relevant changes) the parameters of the main felling volume, tending fellings, fires and treeplanting. Each of these parameters can assume three values: $0 \%$ (none), 50\% (a half of the volume), and 100\% (total volume).

The results of calculations are evaluated using the set of criteria:

1. $\max _{j} \min _{i} W^{j}\left(t_{j}\right)$, where $W^{j}\left(t_{i}\right)$ is the standing crop (for all species and ages) calculated from the $j$-th scenario in the year $t_{i}$;

2. $\min _{j} \max _{i} S_{0}^{j}\left(t_{j}\right)$, where $S_{0}^{j}\left(t_{i}\right)$ is the area "uncovered in forest" calculated from the $j$-th scenario in the year $t i$, in which the forest can grow;

3. $\max _{j}\left(S_{4}^{j}+S_{5}^{j}\right)$, where $S_{4}^{j}\left(t_{i}\right)$, and $S_{5}^{j}\left(t_{i}\right)$, respectively, correspond to the area of mature and overmature forests calculated from the $j$-th scenario for the forecasted period.

4. $\min _{j} \max _{i} S_{5}^{j}\left(t_{j}\right)$, where $S_{5}^{j}\left(t_{i}\right)$ is the area of overmature forests calculated from the $j$-th scenario in the year $t_{i}$.

Each calculated scenario is evaluated using this set of criteria. Multicriteriality is an integral feature of most real choice problems and requires special methods of analysis. In decision making theory where the feasible solutions are evaluated simultaneously from several indices (criteria), the Edgeworth-Pareto principle is widely used; according to this principle, the best solutions should be chosen among the Pareto-optimal solutions [23, 24]. 
Table 1 provides the results derived from identifying a set of Pareto-optimal solutions and the values of the parameters for 10 scenarios for all district forestries of the Irkutsk region. In the "Pareto" column, the value 1 corresponds to the fact that this criterion is involved in this set, and the value 0 means that it is not involved.

Table 1. Results of singling out the Pareto-optimal solutions from 10 modeling scenarios

\begin{tabular}{|l|l|l|l|l|l|}
\hline No. & Pareto & \multicolumn{4}{l}{ Parameters } \\
\hline & & $\begin{array}{l}\text { tending, } \\
\%\end{array}$ & $\begin{array}{l}\text { fellings, } \\
\%\end{array}$ & fires, \% & $\begin{array}{l}\text { planting, } \\
\%\end{array}$ \\
\hline 1 & 1 & 100 & 100 & 100 & 100 \\
\hline 2 & 0 & 0 & 100 & 50 & 0 \\
\hline 3 & 1 & 0 & 100 & 50 & 50 \\
\hline 4 & 0 & 0 & 50 & 100 & 0 \\
\hline 5 & 1 & 50 & 50 & 100 & 0 \\
\hline 6 & 1 & 0 & 50 & 50 & 100 \\
\hline 7 & 0 & 50 & 0 & 100 & 0 \\
\hline 8 & 0 & 0 & 50 & 100 & 0 \\
\hline 9 & 1 & 50 & 0 & 0 & 100 \\
\hline 10 & 0 & 0 & 50 & 50 & 0 \\
\hline
\end{tabular}

Thus, of the 10 scenarios, 5 scenarios were discarded. The optimal scenarios for forest resource management are: 1) the carrying out, in full volume, of main fellings and treeplanting having regard to the current number of fires in the region's forests; 2) no main fellings, the carrying out of tending fellings in full volume, and treeplanting in a half of the volume, and a decrease of the number of fires by a factor of $2 ; 3$ ) the carrying out of main fellings and tending fellings in a half of the volume, and no fires, with the current number of fires; 4) no main fellings, the carrying out of tending fellings in a half of the volume, treeplanting in full volume, a decrease of the number of fires by a factor of $2 ; 5$ ) an increase in forested areas and timber reserves for all age groups no main fellings, the carrying out of tending fellings in a half of the volume, treeplanting in full volume, and no fires.

\section{Results}

The software program system for predictive mapping of the dynamics of forest resources is represented by the intelligent information system featuring a close interaction of the following three subsystems: GIS, mathematical modeling subsystem FMD (Forest management Dynamics), and automation system for logical reasoning (the artificial intelligence system) [25]. Information that is used in identifying the FMD model and calculating the initial conditions represents the database with various forest organization characteristics. Results are represented as cartographic GIS products as well as animation images. 
The FMD model is being used in forecasting the forest resource dynamics on different levels in GIS, namely, region, administrative districts, district forestries, and compartments.

The FMD GIS is developed on the basis of the Java software technology, the selection of which is due to open library OpenMap implemented within the framework of this technology (available together with the source code) for the creation of the GIS [26]. A search on the Internet showed that there are perhaps no open analogues as regards the maturity level. OpenMap is based on the JavaBeans technology ensuring integration both in applications and in Java Applets. The library displays cartographic data and performs a processing of the users' requests for a modification of these data (scaling, movement, addition of words, saving, etc.). The library handles ESRI (shape files) data, data from text files CSV (comma-separated values), and some others. In addition to OpenMap, the system under development uses Java Libraries to visualize graphs, diagrams and calculation results.

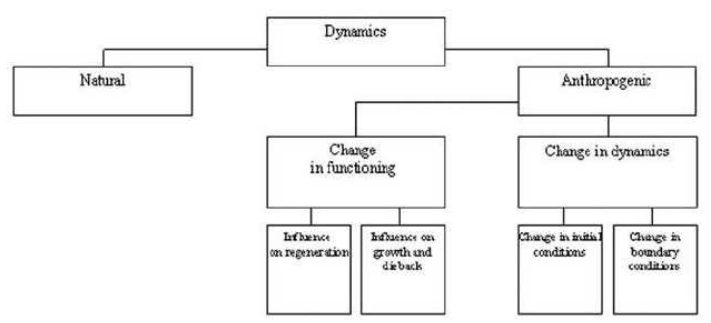

Figure 4: Schematic of control actions on forest

The forest stand dynamics model is implemented by a software module linked with the GIS application on the basis of the OpenMap library. The module realizes the numerical solution to differential equations using the Runge-Kutta method. The module receives data from the database containing information on the conditions of the forest resources, fellings, fires, etc.

Once the data are imported, the software interface module performs calculations in terms of the model by preliminarily choosing one of the variants of the forest resource management strategy (the natural or anthropogenic dynamics). In the latter case, as is known, a human being acts on the system as a whole, altering its dynamics, or on its separate elements, influencing on their functioning. Consequently, in the modeling mode using the anthropogenic dynamics, the course of development of forest stands can also be acted upon by two methods, namely, by altering the initial conditions of forest (tending fellings, main fellings, etc.) or the boundary conditions (abundance of sprouts, overgrowing rtes of the areas uncovered in forest, etc.) (Fig.4). A change of the character of development of the natural system being modeled is represented by the value of the model coefficients related to the rate of the tree regeneration and growth processes.

The calculated data (the distribution of the areas in species and age classes as well as in time) generate the CSV database and are plotted at the user's request. The user specifies by himself the particular combinations of the particular variables to be plotted as time series, including a possibility of representing the data on each individual species as well as for all species in combination.

For representing the results as a cartographic product, the data from the calculated database are transferred to the GIS subsystem, and it is this subsystem that maps them on a corresponding 


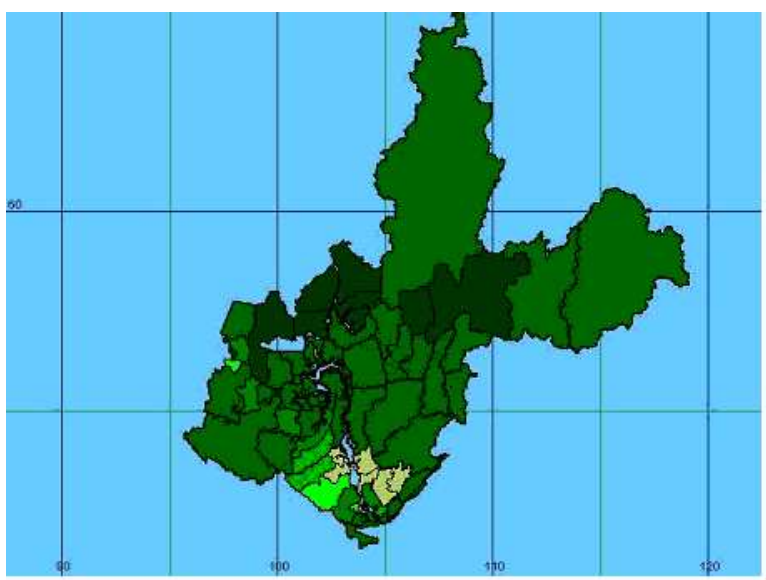

a

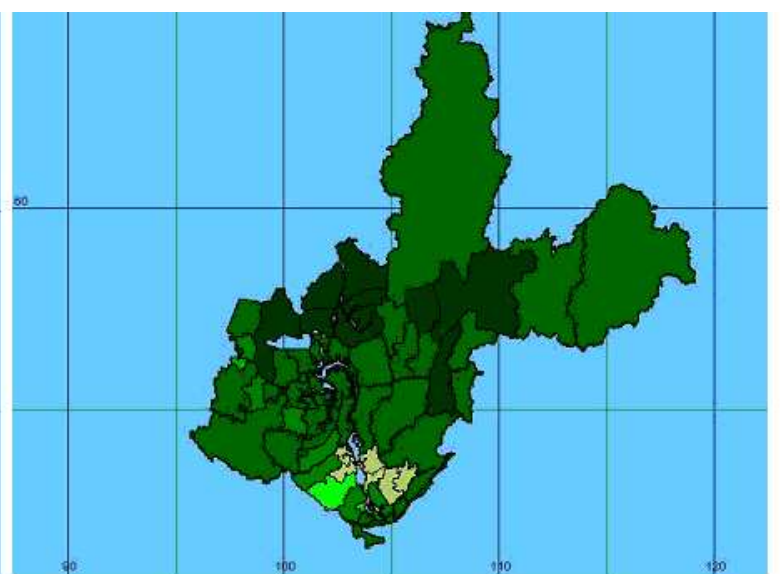

b

Figure 5: The dynamics of natural changes in the distribution of forest resources of coniferous species of a mature and overmature age class ( $a$ - initial instant of time, $b-5$ years later, $c-22$ years later, $d-30$ years later). Different tones show the reserves of forest stands: from light to dark - in order of increasing forest reserves

base. The grid of the boundaries of district forestries is used as the base. To create the cartographic product requires selecting a characteristic of forest resources (the model variable or some mathematical expression for the variables) to be mapped (for instance, the share of the area of forests of coniferous species of maturity age).

The system permits maps to be constructed in terms of the models for any instant of calculated time. Also, there is a possibility of exporting images to a JPEG file with the subsequent creation of animation images. Also, the system furnishes a means of generating, for each stage of calculating the forest dynamics, a new image as a new layer of the thematic map. The dynamics of the object of investigation is represented by a series of mapping layers marked by a corresponding instant of time. When arranged consecutively, these layers generate a cartographic animation portraying spatio-temporal changes in the various characteristics of forests.

Fig. 5 presents the results of calculations in terms of the model for the dynamics of the forest reserves in the district forestries of the Irkutsk region with due regard for the distribution o the forest area in categories, species and age groups (the regional-level model).

Fig. 6 shows the results of calculations of a modeling of the forest dynamics in terms of the subregional model, with due regard for the final felling operations and neglecting reforestation and fires. The direction of the vector of felling in this example is shown in Fig.6 $a$ by the arrow; accordingly, the tree fellings were calculated only for the territory roughly outlined by a triangle. The calculations were carried out for the territory of the Educhansky district forestry of the UstIlimsk district, the maximum felling volume was estimated at 500 thou m3/year, and the maps of the conditions of mature and overmature forests (the relative area of mature and overmature forests vs. total area of the compartment) at the initial time of modeling, and 50 and 100 years later are 


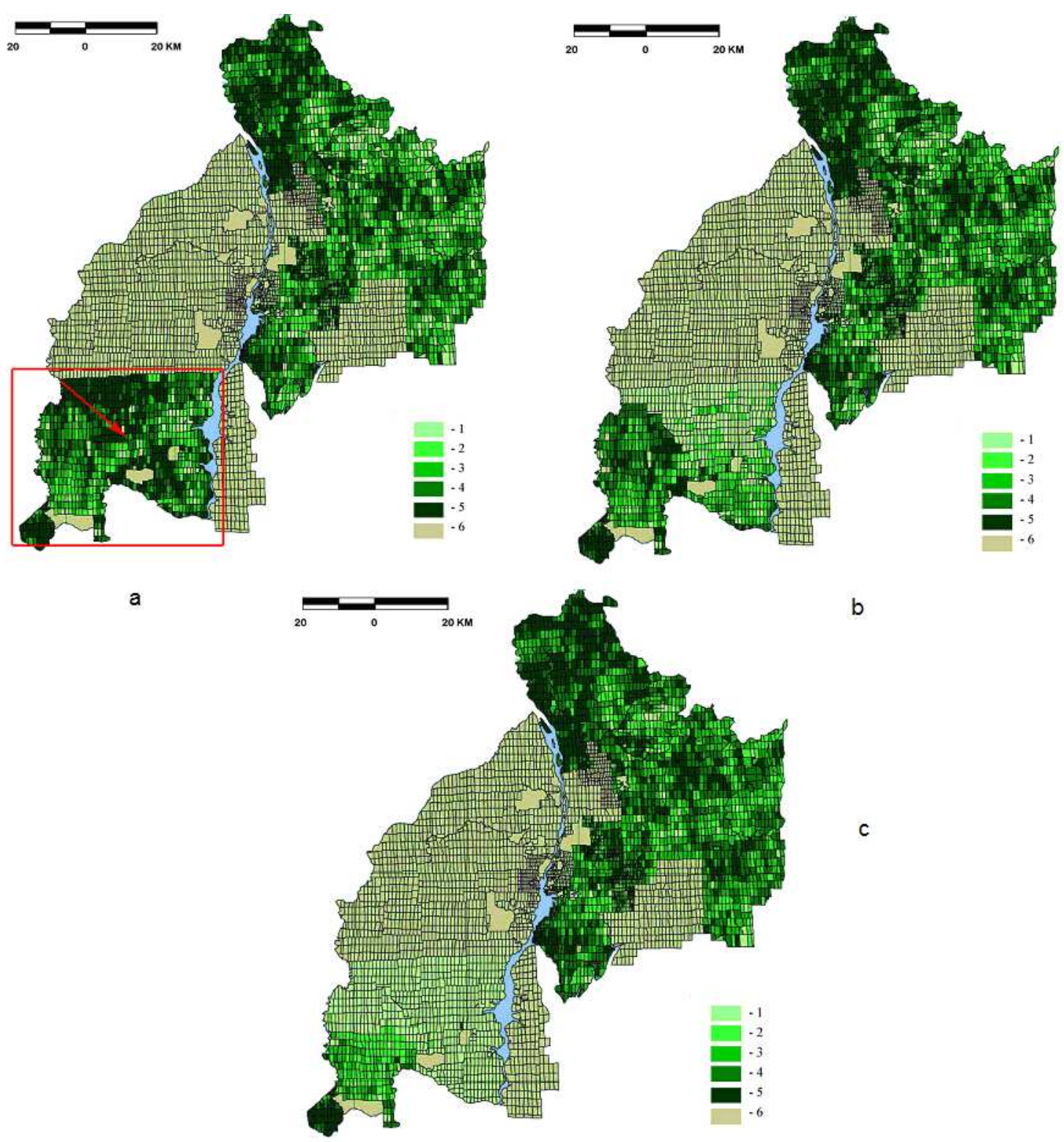

Figure 6: Relative area of mature and overmature forests vs. total area of the compartment. The forest conditions: $a$ - at the beginning of the modeling period, $b-50$ years later, $c-100$ years later. $(1-0-20 \%, 2-20-40 \%, 3-40-60 \%, 4-60-80 \%, 5$ - more than $80 \%, 6$ - no data) 
provided in Fig.6.

\section{Conclusion}

The structure of the models for the dynamics of forest resources, and the methods of their information support naturally follow from the principles of describing forest ecosystems as systems of the dynamical type $[9,13]$. Control actions in them are introduced mostly additively (by adding or subtracting a corresponding control function).

A verification of the dynamical models using extensive data on changes in the conditions of the forest reserves in the Irkutsk region showed a good agreement between calculated and observed characteristics of forests. This makes it possible to carry out predictive calculations of the changes in the conditions of forest resources under different natural regeneration regimes and with varied forms of economic management on different levels.

When predictive dynamical models are developed, it is possible to achieve satisfaction of the uniqueness condition of the solution to the equations by taking into consideration the initial and boundary conditions of the geographical environment. In the latter case, this is done by using the homotopic parameter that determines the values of constants of functional dependencies of the parameters of a natural system. A knowledge of the value of the homotopic parameter provides a means of taking into account the specific character of the conditions and to change, when modeling the dynamics, from some computational equations to the others, which ensures an integral consideration of the physical-geographical characteristics of the study territories.

The final stage in modeling the forest resource dynamics involves dynamical mapping using the aforementioned mathematical models, GIS technologies, space-acquired data, and methods of its processing.

\section{References}

[1] D.J. Connor, B.R. Tunstall, R. Van den Driessche An analysis of photosynthetic response in an brigalow forest. Photosynthetica, 5 (1971), No 3, 218-225.

[2] H.S. Horn. Markovian properties of forest succession. Ecology and Evolution of Communities. Cambridge, Belknap, 1975, 196-211.

[3] H.S. Horn. Some causes of variety in patterns of forest succession. Forest Succession: Concepts and Applications. N.Y., Springer-Verlag, 1991, 24-35.

[4] A.K. Cherkashin. Forecasting the spatial and temporal dynamics of forests of taiga landscape. Dynamics of Ecologo-Economic Systems. Novosibirsk, Nauka, 1981, 107-111.

[5] D.L. Urban, M.E. Harmon, C.B.Halpern. Potential response of Pacific Northwestern forests to climatic change, effects of stand age and initial composition. Climatic Change, 23 (1993), 247-266. 
[6] A. Fischlin, H. Bugmann, D. Gyalistras. Sensitivity of a forest ecosystem model to climate parameterization schemes. Environmental Pollution, 87 (1995), 267-282.

[7] H.K.M. Bugmann. A simplified forest model to study species composition along climate gradients. Ecology, 77 (1996), 2055-2074.

[8] A.V. Benkov, V.A. Ryzhkova. Assessment and modeling of the dynamics of the southern-taiga pine forests in Middle Siberia. Lesovedeniye, 1 (2001), 3-12.

[9] I.N. Vladimirov. Mapping of regenerative and age dynamics of taiga forests on the basis of remote sensing data, geographical knowledge and mathematical models. Journal of Remote Sensing, 11 (2007), No 5, 732-744.

[10] H.H. Shugart, T.R. Crow, J.M. Hett. Forest succession models: a rational and methodology for modeling forest succession over large regions. Forest Science, 19 (1973), No 3, 203-212.

[11] H.H. Shugart. A Theory of forest dynamics. The ecological implications of forest succession models. N.Y., Springer, 1984.

[12] A.K. Cherkashin. The use of a mathematical model in forecasting the recovery of the structure of taiga biogeocenoses after tree felling. Structure and Dynamics of Geosystems. Novosibirsk, Nauka, 1979, 97-110.

[13] A.K. Cherkashin. The model for the dynamics of forest stands of a district forestry and its use in solving prediction problems. Planning and Forecasting of Natural-Economic Systems. Novosibirsk, Nauka, 1984, 69-81.

[14] A.K. Cherkashin. The expanding complex of particular models. Forest. Systemic Research Into a Region's Nature - Economy Interaction. Irkutsk University Publisher, 1986, 71-77.

[15] D.J. Mladenoff, H.S. He. Design and behavior of LANDIS, an object-oriented model of forest landscape disturbance and succession. Advances in Spatial Modeling of Forest Landscape Change: Approaches and Applications. Cambridge University Press, 1999, 125-162.

[16] D.J.Mladenoff, G.E. Host, J. Boeder, T.R. Crow. LANDIS: a spatial model of forest landscape disturbance, succession, and management. GIS and Environmental Modeling: Progress and Research Issues. GIS World Inc., 1996. 175-180.

[17] N.N. Moiseyev. System analysis of dynamical processes of the biosphere. Vestnik AN SSSR, 1 (1979), 97-108.

[18] J. Luan, R.I. Muetzelfeldt, J. Grace. Hierarchical approach to forest ecosystem simulation. Ecological Modelling, 86 (1996), 37-50.

[19] J. Wu, J.L. David. A spatially explicit hierarchical approach to modeling complex ecological systems: theory and applications. Ecological Modelling, 153 (2002), 7-26. 
[20] A. Makela. Process-based modelling of tree and stand growth: towards a hierarchical treatment of multiscale processes. Canadian Journal of Forest Research, 33 (2003), 398-409.

[21] D.C. Bragg, D.W. Roberts, T.R. Crow. A hierarchical approach for simulating northern forest dynamics. Ecological Modelling, 173 (2004), 31-94

[22] I.N. Vladimirov. The uniqueness of predictive dynamical models as the geographical problem. Geography: New methods and Prospects of a Future Advancement: proc. 15th Conf. of Young Geographers of Siberia and the Far East. Institute of Geography SB RAS Publisher, 2003, 155-157.

[23] V.D. Nogin. A logical rationale for the Edgeworth-Pareto principle. Zhurnal vychislitelnoi matematiki i matematicheskoi fiziki, 42 (2002), No. 7, 950-956.

[24] V.D. Nogin. The Edgeworth-Pareto principle and the relative importance of the criteria in the case of a fuzzy preference relation. Zhurnal vychislitelnoi matematiki i matematicheskoi fiziki, 43 (2003), No. 11, 1676-1686.

[25] E.A. Cherkashin, A.K. Chudnenko, I.N. Vladimirov. The intelligent information system for forest stand management dynamics within the context of the problem of developing the decision-making support system for rational utilization of forest resources. InterCarto/InterGIS 10. International Cartographic Association, 2004, 81-85.

[26] I.N. Vladimirov, A.K. Chudnenko. Forecasting of the spatio-temporal dynamics of the forest resources of the Irkutsk region using GIS technologies. Sun. Earth, Water, and Energy. Transactions of the Siberian Division of APVN, issue 2. Novosibirsk, Nauka, 2005, 61-68. 